\title{
PENGARUH ASOSIASI MEREK TERHADAP KEPUTUSAN PEMBELIAN
}

\author{
Coriza Mayasari \\ Department of Management FEB UMM \\ E-mail:qori.dika@gmail.com
}

\begin{abstract}
This research intent to determine the effect of Brand Associations which consists of Intangible Attributes, Benefits to Customers and Relative Prices significant influence the purchase decision and to determine variable dominant Brand Associations on purchasing decisions. This research, data were collected through a questionnaire technique on 100 respondents facial milk cleanser brand in Indomaret Viva by using Judgmental Sampilng techniques. Then performed an analysis of the data obtained through the test instrument using validity test and reliability test. The data analysis technique used is multiple linear regression analysis. Testing instrument through simultaneous test ( $F$ test) and partial test ( $t$ test) data processed resulting equation. Hypothesis testing using test through the coefficient of determination $\left(R^{2}\right)$, it is known that the Adjusted $R^{2}$ indicates that the appropriate regression equation to predict the dependent variable, while the rest is explained by other variables that are not addressed in this study. F test results can be seen all over the independent variables consisting of Intangible Attributes, Benefits for Customers, and the relative price has a significant influence together (simultaneously) to the buying decision. Then the t test showed that the Customer Benefits shown to have a dominant influence on the dependent variable (purchasing decisions).
\end{abstract}

Keyword: Intangible Attributes, Benefits to Customers, Relative Prices, Purchase Decision

\section{PENDAHULUAN}

Merek mempunyai peranan yang bukan sekedar sebagai nama ataupun sebagai pembeda dengan produk-produk pesaing tetapi, merupakan faktor penentu untuk menjadi "trend setter" di bidang industri. Sebuah merek juga dapat membentuk aosiasi dibenak konsumen perusahaan akan dengan mudah dalam memasarkan. Asosiasi merek adalah segala hal yang berkaitan dengan ingatan mengenai sebuah merek (Aaker, 1997). Sebuah merek adalah serangkaian asosiasi, biasanya terangkai dalam berbagai bentuk yang bermakna.

Penelitian ini mengambil 3 variabel karena melihat fenomena secara langsung. Atribut tak berwujud merupakan suatu faktor yang tak berwujud atau dapat dinamakan atribut umum, dalam atribut tak berwujud ini konsumen dapat memberikan presepsi kualitas, dan kesan terhadap merek sesudah 
pembelian yang dilakukan terhadap susu pembersih wajah merek Viva. Manfaat bagi pelanggan biasanya terdapat hubungan antara atribut produk, dalam hal ini pelanggan (konsumen) memberikan tanggapan langsung sesudah pembelian dan penggunaan susu pembersih wajah merek Viva. Konsumen memilih susu pembersih wajah Viva karena produk tersebut memiliki harga yang relatif murah sehingga banyak konsumen yang melakukan pembelian terusmenerus.

Namun, dari berbagai merek susu pembersih terdapat lima merek yang berhasil mencapai top brand index, lima merek susu pembersih dapat dilihat pada Tabel 1 Top Brand Index kategori Susu Pembersih Muka (SWA, 2013).

Tabel 1. Top Brand Index Susu Pembersih Muka

\begin{tabular}{lccc}
\hline Merek & $\mathbf{2 0 1 1}$ & $\mathbf{2 0 1 2}$ & $\mathbf{2 0 1 3}$ \\
\hline Viva & 62,0 & 59,3 & 63,9 \\
Sariayu & 33,0 & 32,3 & 32,6 \\
Pond's & 31,3 & 35,1 & 31.3 \\
Mustika ratu & - & - & 26,6 \\
Ovale & 26,1 & 27,9 & 26,1 \\
\hline \multicolumn{4}{l}{ Sumber: Majalah SWA 2013}
\end{tabular}

Pada Tabel 1 dijelaskan bahwa susu pembersih wajah viva menjadi urutan pertama dengan perolehan tahun 2011 sebesar $62,0 \%$, tahun 2012 menurun sebesar 59,3\% dan tahun 2013 meningkat dengan perolehan sebesar 63,9\%. Susu pembersih Viva mendapatkan penghargaan dalam 3 tahun belakangan ini, dikarenakan banyak para konsumen yang mengetahui dan mengingat produk susu pembersih viva sebagai susu pembersih yang terbaik dengan relatif harga yang murah dan bermanfaat bagi permasalahan kulit. Berdasarkan uraian di atas, maka penulis menarik untuk ditulis skripsi dengan mengangkat judul: "Pengaruh Asosiasi Merek Terhadap Keputusan Pembelian (Studi Pada Susu Pembersih Wajah Viva di Indomaret Desa Dlanggu Kab. Mojokerto)”.

Rumusan penelitian ini adalah Apakah asosiasi merek yang terdiri dari atribut tak berwujud, manfaat bagi pelanggan, dan harga relatif berpengaruh signifikan terhadap keputusan pembelian susu pembersih wajah merek viva? Variabel apakah dari asosiasi merek yang berpengaruh dominan terhadap keputusan pembelian? Sedangkan tujuan dalam penelitian ini adalah untuk mengetahui pengaruh asosiasi merek yang terdiri dari atribut tak berwujud, manfaat bagi pelanggan, dan harga relatif terhadap keputusan pembelian. Untuk mengetahui variabel asosiasi merek yang dominan terhadap keputusan pembelian.

\section{TINJAUAN PUSTAKA}

Islam, dkk (2010) melakukan penelitian tentang Pengaruh Kesadaran Merek, Asosiasi Merek, dan Kesan Kualitas Terhadap Keputusan Membeli Ponsel Merek Nokia di Semarang di Semarang". Hasil hipotesis melalui uji $\mathrm{F}$ dan uji $\mathrm{t}$ diketahui bahwa variabel independen dan variabel dependen berpengaruh simultan dan parsial terhadap keputusan pembelian. Uji $t$ menunjukkan bahwa variabel yang paling dominan berpengaruh secara parsial atau individu adalah kesadaran merek. 
Aji (2011) melakukan penelitian tentang Pengaruh Asosiasi Merek terhadap Keputusan Pembelian konsumen produk sabun pencuci piring merek sunlight Malang. Hasil hipotesis melalui uji $\mathrm{F}$ dan $t$ diketahui bahwa semua variabel independen berpengaruh signifikan secara simultan terhadap keputusan pembelian. Melalui uji t bahwa variabel kualitas produk yang dominan berpengaruh signifikan terhadap keputusan pembelian.

Menurut Aaker (1996), menyatakan bahwa merek merupakan nama dan atau simbol (seperti logo, merek dagang atau desain kemasan) atau kombinasinya yang mengidentifikasikan suatu perusahan. Pengertian asosiasi merek yang dikemukakan oleh Aaker (1996) adalah "segala hal yang berkaitan dengan ingatan mengenai merek". Asosiasi akan menjadi faktor yang penting, jika merek yang dimiliki oleh produsen mirip dalam hal atribut dengan merek lainnya atau jika perusahaan merupakan hal penting untuk dilihat.

Menurut Aaker (1997:167), acuan asosiasi merek terdiri dari 11 variabel mengambil 3 variabel yaitu: Atribut tidak Berwujud yaitu suatu faktor tak berwujud merupakan atribut umum seperti halnya persepsi kualitas, kemajuan teknologi, kesan nilai dan inovasi yang mengikhtisarkan serangkaian atribut objektif. Manfaat bagi Pelanggan yaitu biasanya terdapat hubungan antara atribut produk dan manfaat bagi pelanggan, terdapat dua manfaat bagi pelanggan yaitu: Manfaat rasional (rational benefit), adalah manfaat yang berkaitan erat dengan suatu atribut produk dari produk yang dapat menjadi bagian dari proses pengambilan keputusan. Manfaat psikologis (psychological benefit), sering kali merupakan konsekuensi ekstrim dalam proses pembentukan sikap, berkaitan dengan perasaan yang ditimbulka ketika membeli atau menggunakan merek tertentu.

Harga Relatif merupakan evaluasi terhadap merek disebagian kelas produk ini akan diawali dengan penentuan posisi merek tersebut dalam satu atau dua dari tingkat harga. Harga relatif akan memberikan pengaruh pada pelanggan dalam memutuskan membeli produk. $\mathrm{H}$ arga memiliki 2 elemen yaitu harga relatif murah dan harga stabil.

Keputusan pembelian merupakan kegiatan individu yang secara langsung terlibat dalam pengambilan keputusan untuk melakukan pembelian terhadap produk yang ditawarkan oleh penjual. Menurut Kotler (2002:204), tahaptahap yang dilewati pembeli untuk mencapai keputusan membeli ada 5 tahap atau proses pembelian diantaranya dapat dilihat pada Gambar 1.

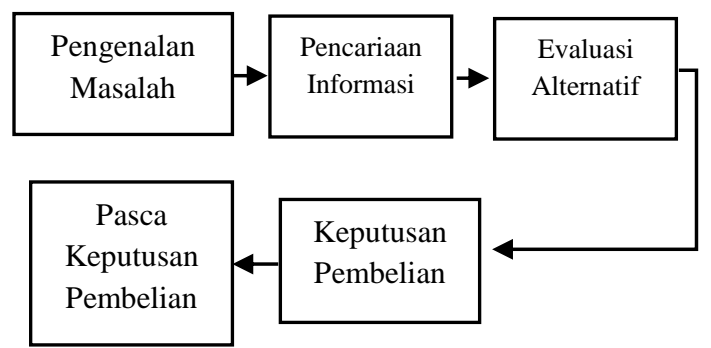

Sumber: Kotler 2002:204

Gambar 1. Model Keputusan

Pembelian

Kerangka pemikiran dalam penelitian ini menggambarkan hubungan dari variabel independen, dalam hal ini adalah asosiasi merek (X) terdiri dari atribut tak berwujud (X1), manfaat bagi pelanggan (X2), 
dan harga relatif (X3), terhadap variabel dependen (Y) yang dilakukan oleh konsumen. Kerangka pemikiran akan dijelaskan pada gambar 2.

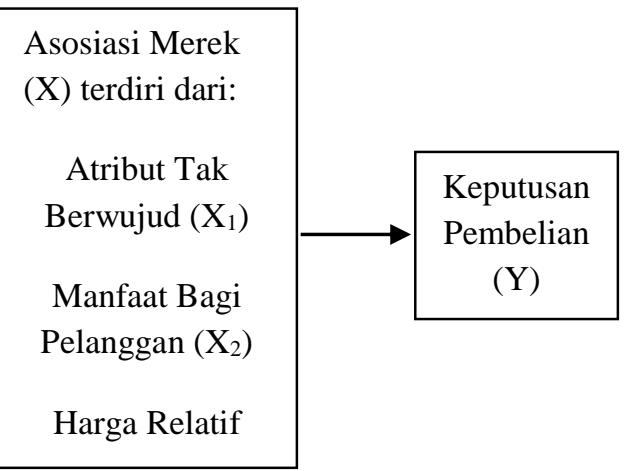

Gambar 2. Kerangka Pemikiran

Hipotesis yang diuji pada penelitian ini adalah:

H1: pengaruh asosisasi merek yang terdiri dari atribut tak berwujud, manfaat bagi pelanggan, dan harga relatif signifikan terhadap keputusan pembelian susu pembersih wajah merek Viva.

$\mathrm{H} 2$ : diduga variabel asosiasi merek yang dominan pada keputusan pembelian konsumen susu pembersih wajah merek Viva yaitu manfaat bagi pelanggan.

\section{METODE PENELITIAN}

Lokasi penelitian pada konsumen susu pembersih wajah merek Viva di Indomaret Desa Dlanggu, Kecamatan Dlanggu, Kabupaten Mojokerto akan dijadikan target. Penelitian yang digunakan adalah penelitian deskriptif dengan metode survey. Sugiyono (2003:11) menyatakan bahwa, penelitian deskriptif adalah: Penelitian yang dilakukan untuk mengetahui nilai variabel mandiri, baik satu variabel atau lebih (independen) tanpa membuat perbandingan, atau menghubungkan dengan variabel yang lain.

Definisi operasional merupakan penentuan abstraksi fenomena-fenomena kehidupan nyata yang diamati sehingga menjadi variabel yang diukur (Indrianto dan Supomo, 1995: 85). Definisi operasional dari masing-masing variabel dalam penelitian ini sebagai berikut: Variabel Bebas / Independent Variable yang akan digunakan dalam penelitian ini adalah Asosiasi Merek adalah sebuah ingatan (memory) yang ada pada benak konsumen tentang merek suatu produk.

Asosiasi merek terdiri dari atribut tak berwujud (X1), suatu faktor yang mengikhtisari pada beberapa persepsi kualitas, kesan nilai dan inovasi. Manfaat bagi pelanggan (X2), sebagian besar atribut produk/jasa memberi manfaat bagi pelanggan, maka biasanya terdapat hubungan antar keduanya. Harga Relatif (X3), sebuah merek memberikan jaminan harga yang optimum agar dapat memposisikan diri dengan merek-merek yng lain pada tingkat harga yang sama.

Variabel Terikat/ Dependent Variablep pada penelitian ini adalah keputusan pembelian, dimana keputusan pembelian merupakan suatu aktivitas konsumen dalam membentuk tujuan atau maksud untuk membeli produk yang diinginkan.

Populasi merupakan keseluruhan dari kumpulan elemen yang memiliki sejumlah karakteristik umum, yang merupakan wilayah (dimana) penelitian tersebut akan digeneralisasi (Widayat, 2004). Populasi yang akan diteliti dalam penelitian ini adalah konsumen 
wanita remaja maupun dewasa yang memutuskan membeli susu pembersih wajah di Indomaret Desa Dlanggu Kabupaten Mojokerto.

Metode yang digunakan Judgemental Sampling maka penelitian ini akan menggunakan sampel 100 responden wanita remaja maupun dewasa umur 17-32 tahun yang memutuskan membeli di Indomaret Desa Dlanggu Kabupaten Mojokerto yang memutuskan membeli susu pembersih wajah merek viva banyak melihat dari hasil Top Brand Index dan fenomena secara langsung.

Menurut Maholtra (2005:120) data primer merupakan data yang dibuat oleh peneliti untuk menyelesaikan riset. Data primer penelitian ini diperoleh dari kuisioner Data Sekunder. Menurut Maholtra (2005:121) data sekunder merupakan data yang dikumpulkan untuk maksud selain untuk menyelesaikan masalah yang sedang dihadapi. Data sekunder merupakan data pendukung yang digunakan pada penelitian ini. Data sekunder yang dibutuhkan pada penelitian ini berupa profil perusahaan, internet dan jurnal.

Menurut Widayat (2004:120) kuisioner adalah daftar pertanyaan atau pertanyaan yang dikirimkan kepada responden baik secara langsung maupun tidak langsung (melalui pos, internet atau perantara) untuk memperoleh informasi yang dibutuhkan.

Menurut

Maholtra

(2005:298), skala likert adalah skala pengukuran dengan lima kategori respon yang berkisar antara" sangat setuju" hingga "sangat tidak setuju". Menurut Arikunto (2004), validitas adalah ukuran yang digunakan untuk menunjukkan tingkat kevalidan suatu instrument. Adapun kriteria pengujiannya adalah apabila $r$ hitung $\geq \mathrm{r}$ tabel, maka data yang digunakan dinyatakan valid dan sebaliknya apabila $r$ hitung < $r$ tabel maka data dinyatakan tidak valid.

Menurut Widayat (2004:85), reliabilitas menunjuk pada satu pengertian bahwa suatu dikatakan memiliki reliabilitas apabila instrument yang digunakan beberapa kali untuk mengukur objek yang sama.

Adapun penggunaan analisis regresi berganda bertujuan untuk menghitung besarnya pengaruh secara kuantitatif dari suatu perubahan kejadian (variabel $\mathrm{X}$ ) terhadap kejadian lainnya (variabel Y), dimana dalam penelitian ini dikonversikan untuk menguji ada tidaknya pengaruh variabel-variabel terhadap keputusan pembelian. Rumus regresi linier berganda yang digunakan dalam penelitian:

$Y=a+b_{1} X_{1}+b_{2} X_{2}+b_{3} X_{3}+e$

Pengujian hipotesis dalam penelitian ini menggunakan bantuan komputer yaitu program SPSS (Statistical Package for Social Sciences) 17. Uji koefisien determinasi $\left(\mathrm{R}^{2}\right)$ digunakan untuk mengukur seberapa jauh kemampuan model dalam menerangkan variasi variabel dependen (Ghozali, 2005). Nilai $\mathrm{R}^{2}$ yang semakin mendekati 1 , berarti variabel-variabel independen memberikan hampir semua informasi yang dibutuhkan untuk memprediksi variasi variabel independen.

Uji F/ Uji Koefisien Regresi Secara Simultan. Tingkat kepercayaan yang digunakan 95 
persen atau taraf signifikan 5\% dengan kriteria sebagai berikut: Jika $\mathrm{F}_{\text {hitung }}>\mathrm{F}_{\text {tabel }} \mathrm{Ha}$ diterima dan Ho ditolak, berarti variabel independen secara bersama-sama mempunyai pengaruh signifikansi terhadap variabel dependen. Jika $F_{\text {hitung }} \leq \mathrm{F}_{\text {tabel }}$ Ho diterima dan Ha ditolak, berarti variabel independen secara bersamasama tidak mempunyai pengaruh signifikansi terhadap variabel dependen.

Uji T / Uji Koefisien Regresi Secara Parsial. Tingkat kepercayaan yang digunakan 95 persen / taraf signifikansi adalah 5\% dengan kriteria penilaian sebagai berikut: Jika $t_{\text {hitung }}>\mathrm{t}$ tabel Ha diterima dan Ho

ditolak, berarti ada pengaruh yang signfikan antara masing-masing variabel independen dan variabel dependen. Jika $\mathrm{t}$ hitung $\leq \mathrm{t}$ tabel Ho diterima dan Ha ditolak, berarti tidak ada pengaruh yang signfikan antara masing-masing variabel independen dan variabel dependen.

\section{HASIL PENELITIAN DAN PEMBAHASAN}

Gambaran umum responden berdasarkan usia dari remaja 17 tahun samapi dewasa 47 tahun yang memutuskan untuk membeli susu pembersih wajah merek Viva. Oleh sebab itu, pada tabel 2 akan dijelaskan presentase pembelian yang dilakukan responden khususnya wanita remaja maupun dewasa.

Berdasarkan Tabel 2, sebagian besar responden dengan usia 28-32 tahun yang melakukan pembelian susu pembersih wajah merek viva sebesar 29\%. Usia tersebut merupakan usia wanita dewasa yang peduli dengan kecantikan dan kesehatan kulit sehingga sebagian besar melakukan pembelian secara berulang.

Tabel 2. Persentase Usia Responden

\begin{tabular}{ccc}
\hline $\begin{array}{c}\text { Usia } \\
\text { (tahun) }\end{array}$ & $\begin{array}{c}\text { Jumlah } \\
\text { (orang) }\end{array}$ & Presentase \\
\hline $17-22$ & 19 & $19 \%$ \\
$23-27$ & 27 & $27 \%$ \\
$28-32$ & 29 & $29 \%$ \\
$33-37$ & 12 & $12 \%$ \\
$38-42$ & 8 & $8 \%$ \\
$43-47$ & 5 & $5 \%$ \\
Total & 100 & $100 \%$ \\
\hline \multicolumn{2}{l}{ Sumber: data primer diolah, 2014 }
\end{tabular}

Gambaran umum responden berdasarkan pekerjaan yang memutuskan membeli susu pembersih wajah merek Viva dari berbagai pekerjaan yang akan dijelaskan dalam Tabel 3 presentase berdasarkan pekerjaan para responden wanita.

Tabel 3. Presentase Pekerjaan Responden

\begin{tabular}{lcc}
\hline Pekerjaan & $\begin{array}{c}\text { Jumlah } \\
\text { (orang) }\end{array}$ & Presentase \\
\hline Pelajar & 19 & $19 \%$ \\
Wiraswasta & 17 & $17 \%$ \\
Pedagang & 9 & $9 \%$ \\
PNS & 6 & $6 \%$ \\
Guru & 12 & $12 \%$ \\
Perawat & 10 & $10 \%$ \\
Bidan & 5 & $5 \%$ \\
Pengusaha & 3 & $3 \%$ \\
Dokter & 4 & $4 \%$ \\
IRT & 15 & $15 \%$ \\
$\quad$ Total & 100 & $100 \%$ \\
\hline Sumber: Data primer diolah, 2014
\end{tabular}

Berdasarkan Tabel 3 menunjukkan bahwa responden yang memiliki pekerjaan sebagai pelajar dalam melakukan pembelian susu 
pember,sih wajah merek Viva sebesar 19\%. Uji validitas dapat dilihat pada Tabel 4.

\begin{tabular}{ccccc}
\multicolumn{5}{c}{ Tabel 4. Tabel Uji Validitas Variabel } \\
\hline Variabel & Item/kode & $\mathrm{r}$ Hitung & $\mathrm{r}$ Tabel & Ket. \\
\hline Atribut Tak Berwujud & $\mathrm{X} 11$ & 0,576 & 0,197 & Valid \\
(X1) & & & & \\
& $\mathrm{X} 12$ & 0,542 & 0,197 & Valid \\
& $\mathrm{X} 13$ & 0,553 & 0,197 & Valid \\
Manfaat Bagi & $\mathrm{X} 21$ & 0,569 & 0,197 & Valid \\
Pelanggan (X2) & $\mathrm{X} 22$ & 0,569 & 0,197 & Valid \\
Harga Relatif(X3) & $\mathrm{X} 31$ & 0,562 & 0,197 & Valid \\
& $\mathrm{X} 32$ & 0,562 & 0,197 & Valid \\
Keputusan Pembelian & $\mathrm{Y} 1$ & 0,720 & 0,197 & Valid \\
(Y) & $\mathrm{Y} 2$ & 0,651 & 0,197 & Valid \\
& $\mathrm{Y} 3$ & 0,592 & 0,197 & Valid \\
\hline Sumber:Data primer diolah 2014 & & & &
\end{tabular}

Berdasarkan Tabel 4 dapat diketahui bahwa memiliki $\mathrm{r}$ hitung (Corrected Item - Total Correlation) $\geq \mathrm{r}$ tabel, maka dapat disimpulkan bahwa seluruh item pernyataan (indikator) yang terdapat dalam seluruh variabel tersebut adalah valid. Hasil pengujian reliabilitas dapat dilihat pada Tabel 5.
Tabel 6. Coefficient Regresi

\begin{tabular}{|c|c|c|c|c|}
\hline \multirow{2}{*}{ Variabel } & \multicolumn{2}{|c|}{$\begin{array}{c}\text { Unstandrdized } \\
\text { Coefficients }\end{array}$} & \multirow{2}{*}{$\mathrm{t}$} & \multirow{2}{*}{ Sig. } \\
\hline & B & $\begin{array}{r}\text { Std. } \\
\text { Error }\end{array}$ & & \\
\hline Constant & 1.175 & 1.421 & 0.82 & 0.41 \\
\hline $\begin{array}{l}\text { Atribut } \\
\text { Tak }\end{array}$ & 0.337 & 0.097 & 3.46 & 0.01 \\
\hline $\begin{array}{c}\text { Bewujud } \\
\left(\mathrm{X}_{1}\right)\end{array}$ & & & & \\
\hline $\begin{array}{l}\text { Manfaat } \\
\text { Bagi }\end{array}$ & 0.504 & 0.139 & 3.62 & 0 \\
\hline $\begin{array}{l}\text { Pelangga } \\
\mathrm{n}\left(\mathrm{X}_{2}\right)\end{array}$ & & & & \\
\hline $\begin{array}{c}\text { Harga } \\
\text { Relatif } \\
\left(\mathrm{X}_{3}\right) \\
\end{array}$ & 0.284 & 0.134 & 2.12 & 0.03 \\
\hline
\end{tabular}

Penelitian ini digunakan hasil uji regresi yang Unstandardized dikarenakan untuk menyamakan ukuran variabel independen (Atribut Tak Berwujud $\left(\mathrm{X}_{1}\right)$, Manfaat Bagi Pelanggan $\left(\mathrm{X}_{2}\right)$, dan Harga Relatif $\left(\mathrm{X}_{3}\right)$ ) yang tidak sama. Keuntungan menggunakan hasil regresi yang Unstandardized digunakan karena

Tabel 5. Tabel Uji Reliabilitas Variabel

\begin{tabular}{lccc}
\hline \multicolumn{1}{c}{ Variabel } & $\begin{array}{c}\text { Nilai Cronnbach } \\
\text { Alpha }\end{array}$ & $\begin{array}{c}\text { Tolok } \\
\text { Ukur }\end{array}$ & \multirow{2}{*}{ Ket } \\
\hline Atribut Tak Berwujud (X1) & 0,733 & 0,60 & Reliabel \\
Manfaat bagi Pelanggan (X2) & 0,725 & 0,60 & Reliabel \\
Harga Relatif (X3) & 0,719 & 0,60 & Reliabel \\
Keputusan Pembelian (Y) & 0,803 & 0,60 & Reliabel \\
\hline Sur
\end{tabular}

\section{Sumber: Data primer diolah, 2014}

Hasil pengujian menunjukkan

nilai Cronbach Alpha dari keseluruhan variabel adalah lebih besar dari 0,60 sehingga dapat disimpulkan bahwa variabel yang digunakan adalah reliabel. Hasil uji regresi linier berganda diperoleh koefisien regresi, nilai t hitung dan tingkat signifikansi sebagaimana ditampilkan pada Tabel 6 . ingin melihat tingkat prioritas. koefisien determinasi $\left(\mathrm{R}^{2}\right)$ menunjukkan besarnya Adjusted $R^{2}$ adalah 0,346, hal ini berarti $34,6 \%$ variasi Keputusan pembelian dapat dijelaskan oleh variasi dari ke 3 variabel independen, yaitu Harga Relatif $\left(\mathrm{X}_{3}\right)$, Atribut Tak Berwujud 
$\left(\mathrm{X}_{1}\right)$, dan Manfaat Bagi Pelanggan

$\left(\mathrm{X}_{2}\right)$. Sedangkan sisanya sebesar $65,4 \%(100 \%$ - 34,6\%) dijelaskan oleh variabel lain yang tidak dibahas dalam penelitian ini. Pada tabel 7 akan dijelaskan hasil pengujiannya sebagai berikut:

Tabel 7. Hasil Uji Koefisien Determinasi $\left(\mathrm{R}^{2}\right)$

\begin{tabular}{lcc}
\hline Variabel & $\begin{array}{c}\text { Adjusted } \\
\mathrm{R} \\
\text { Square }\end{array}$ & $\begin{array}{c}\text { Std. Error of } \\
\text { the Estimate } \\
(\mathrm{SEE})\end{array}$ \\
\hline $\begin{array}{l}\text { Harga relatif }\left(\mathrm{X}_{3}\right) \\
\text { Atribut tak }\end{array}$ & 0.346 & 1.753 \\
Berwujud $\left(\mathrm{X}_{1}\right)$ & & \\
Manfaat Bagi & \\
Pelanggan $\left(\mathrm{X}_{2}\right)$ & \\
\hline Sumber: Data primer diolah, 2014 \\
\multicolumn{1}{c}{ Pada tabel 8 akan dijelaskan } \\
pengujiannya sebagai berikut: \\
Tabel 8. Hasil Uji Simultan (Uji F)
\end{tabular}

\begin{tabular}{lrrrrr} 
Model & $\begin{array}{c}\text { Sum of } \\
\text { Squares }\end{array}$ & Df & $\begin{array}{c}\text { Mean } \\
\text { Square }\end{array}$ & F & Sig. \\
\hline Reg. & 169.8 & 3 & 56.6 & 18.4 & $0.0^{\mathrm{a}}$ \\
Residl & 294.9 & 96 & 3.1 & & \\
Total & 464.8 & 99 & & & \\
Sumber: Data primer diolah, 2014 & &
\end{tabular}

Berdasarkan pada Tabel 8 Uji simultan atau Uji $\mathrm{F}$ didapat nilai $\mathrm{F}$ Hitung sebesar 18,424 dengan probabilitas 0,000 . Karena F Hitung 18,424 > F tabel 2,70 dan probabilitas jauh lebih kecil 0,05 maka model regresi dapat digunakan untuk memprediksi Keputusan Pembelian atau dapat dikatakan bahwa seluruh variabel independen yaitu Harga Relatif, Atribut tak Berwujud dan Manfaat Bagi Pelanggan secara bersama-sama berpengaruh terhadap variabel dependen (Keputusan pembelian Konsumen).

Pada Tabel 9 dijelaskan pengujiannya sebagai berikut:
Tabel 9. Hasil Uji Parsial (Uji Statistik t)

\begin{tabular}{llll}
\hline Variabel & $t_{\text {hitung }}$ & $t_{\text {tabel }}$ & Sig. \\
\hline $\begin{array}{l}\text { Manfaat } \\
\text { Bagi }\end{array}$ & & & \\
$\begin{array}{l}\text { Pelanggan } \\
\text { (X) }\end{array}$ & & & \\
& & & \\
Sumber: Data primer yang diolah, 2014
\end{tabular}

Pada Tabel 9 menunjukkan bahwa variabel manfaat bagi pelanggan terhadap keputusan pembelian dengan melihat hasil analisis uji $t$ adalah nilai thitung pada variabel Manfaat Bagi Pelanggan $\left(\mathrm{X}_{2}\right)$ adalah 3,628 dengan tingkat signifikansi 0,001 . Karena nilai $t$ hitung 3,628 > nilai t tabel 1,660 dan tingkat signifikansi $0,000 \leq$ probabilitas signifikansi $\alpha=0,05$, maka Ho ditolak dan Ha diterima. Hal ini berarti variabel manfaat bagi pelanggan secara parsial (individual) berpengaruh signifikan terhadap Keputusan Pembelian konsumen.

Berdasarkan pada hasil uji koefisien determinasi $\left(\mathrm{R}^{2}\right)$, variasi keputusan pembelian dapat dijelaskan oleh variasi dari ke 3 varabel independen yang terdiri dari atribut tak berwujud, manfaat bagi pelanggan dan harga relatif. Sedangkan sisanya dijelaskan oleh variabel lain yang tidak dibahas dalam penelitian ini.

Berdasarkan pada hasil uji $\mathrm{F}$, menunjukkan bahwa seluruh variabel independen yang terdiri dari atribut tak berwujud, manfaat bagi pelanggan dan harga relatif secara bersama-sama mempunyai pengaruh signifikan terhadap keputusan pembelian. Berdasarkan pada hasil uji $\mathrm{T}$, menunjukkan bahwa variabel yang dominan berpengaruh terhadap 
keputusan pembelian adalah manfaat bagi pelanggan.

Berdasarkan pada hasil persamaan regresi linier berganda, menunjukkan bahwa varabel independen yang terdiri dari atribut tak berwujud, manfaat bagi pelanggan dan harga relatif mempunyai pengaruh signifikan terhadap keputusan pembelian.

\section{SIMPULAN}

Berdasarkan pada hasil penelitian dan pembahasan mengenai pengaruh asosiasi merek terhadap keputusan pembelian, maka dapat diambil beberapa kesimpulan. Secara Simultan terbukti bahwa variabel atribut tak berwujud, manfaat bagi pelanggan dan harga relatif secara bersama-sama mempunyai pengaruh signifikan terhadap keputusan pembelian. Oleh sebab itu, $\mathrm{H}_{1}$ : pengaruh aosiasi merek yang terdiri dari atribut tak berwujud, manfaat bagi pelanggan dan harga relatif signifikan terhadap keputusan pembelian susu pembersih wajah merek Viva diterima.

Hasil dari pengujian parsial terbukti bahwa variabel yang dominan berpengaruh terhadap keputusan pembelian adalah manfaat bagi pelanggan yang memiliki nilai koefisien regresi lebih besar dibandingkan dengan variabel dependen lainnya. Oleh sebab itu, $\mathrm{H}_{2}$ : variabel asosiasi merek yang dominan berpengaruh pada keputusan pembelian konsumen susu pembersih wajah merek Viva yaitu manfaat bagi pelanggan.

Berdasarkan hasil penelitian, variabel yang dominan berpengaruh terhadap keputusan pembelian konsumen adalah manfaat bagi pelanggan. Hal ini menunjukkan bahwa faktor manfaat bagi pelanggan mempunyai pengaruh yang besar terhadap keputusan pembelian, maka Viva memelihara manfaat bagi pelanggan dengan cara mempertahankan dan menjaga kualitas produknya, dan berinovasi dalam varian yang sesuai permasalahan kulit

\section{DAFTAR PUSTAKA}

Aaker, David. 1996. Building Strong Brand. Fourth Edition. New York. Free Pres. Hal. 106 Dikutip dalam buku Freddy Rangkuti. 2002. The Power of Brand. Jakarta. PT Gramedia Pustaka Utama. Hal.43 1997. "Manajamen Ekuitas Merek: memanfaatkan nilai dari suatu merek".Hal. 162-166. Dikutip dalam jurnal Meidianingsih, Rina. 2008. Analisis Pengaruh Ekuitas Merek Terhadap Keputusan Pembelian Studi Kasus Pada Minuman Teh Siap Saji Frestea.

Aji, Bagus. S. 2011. Pengaruh Asosiasi Merek (Brand Association) terhadap Keputusan Pembelian (Survei Konsumen Produk Sabun Pencuci Piring Merek Sunlight di Desa Tegalsari Kecamatan Kepanjen Kabupaten Malang).

Arikunto, Suharsini. 2004. Dasardasar Manajemen Suatu Pendekatan Praktek. Jakarta: Rineka Cipta.

Indriantoro, Nur dan Supomo, Bambang. 1995. Metodologi Penelitian Bisnis. Yogyakarta. BPFE Yogyakarta. 
Islam, Darul, Suryawinata, Yahya dan Arief, Mohammad. 2010. Pengaruh Kesadaran Merek, Asosiasi Merek, dan Kesan Kualitas Terhadap Keputusan Membeli Ponsel Merek Nokia (Studi Pada Mahasiswa Universitas Trunojoyo).

Kotler, Philip. 2004. Marketing Management.
Millenium Edition. New Jersey Prentice Hall International Inc. Hal. 90.

Maholtra, Naresh. K. 2005. Riset Pemasaran. Jilid 1. PT. Indeks Kelompok Gramedia. Jakarta.

Majalah Swa 2013 diambil pada tanggal 17 Maret 2014.

Widayat. 2004. Metode Penelitian Pemasaran. Malang. UMM press 